\title{
Abordagem das Dificuldades de Ensino e Aprendizagem do \\ Domínio da Estatística na Graduação em Psicologia: um olhar através do contrato didático
}

\author{
Approaching Challenges in Teaching Learning Process of Statistics in \\ Psychology Graduation Courses: a didatic contract overlook
}

\author{
Giselda Magalhães Moreno Nóbrega* \\ ORCID iD 0000-0001-8204-5437 \\ Jorge Tarcísio da Rocha Falcão** \\ ORCID iD 0000-0002-2798-3727
}

\begin{abstract}
Resumo
O ensino de conteúdos conceituais, competências e habilidades relacionados à análise quantitativa de dados nos cursos de graduação em Psicologia tem se mostrado problemático. Enquanto domínio da Matemática, a Estatística de fato se distancia dos saberes usualmente trabalhados nas demais disciplinas. O estudo em questão buscou investigar aspectos presentes na estruturação da sala de aula de uma disciplina de Estatística oferecida no curso de Psicologia. Para isso elegeu-se o contrato didático como um caminho teórico, uma "lente" através da qual fosse possível olhar a dinâmica de funcionamento da sala de aula, buscando aspectos que pudessem estar relacionados às dificuldades do processo ensino-aprendizagem. Buscando enriquecer a análise da dinâmica de funcionamento da disciplina, optou-se por compará-la com uma disciplina "típica" da cultura contratual do curso de Psicologia. Além dos registros audiovisuais das aulas, esse estudo contou com a realização de entrevistas com as professoras das referidas disciplinas. Esses dados foram integrados e em seguida submetidos a uma análise clínicointerpretativa, que apontou diversos fatores de diferenciação entre as duas disciplinas, entre eles a dinâmica de funcionamento das aulas e o sistema de avaliação. Especificamente em relação à disciplina de Estatística, constatou-se aspectos importantes interferindo negativamente no contexto de aprendizagem, como a manipulação excessiva de algoritmos estatístico-matemáticos sem recorrer a ambientes informatizados para tratamento de dados. O estudo chama a atenção para a importância de se ter clareza quanto a ementa, objetivos e organização da disciplina de estatística nos cursos de Psicologia, de modo a traçar caminhos de aprimoramento didáticopedagógico para sua oferta.
\end{abstract}

Palavras-chave: Contrato Didático. Estatística. Psicologia.

\begin{abstract}
Teaching concepts, competences and skills related to data analysis in Psychology graduation courses has proved to be a challenging issue. In the sphere of Mathematic skills, Statistics is indeed out of the scope of what is usually

\footnotetext{
* Doutora em Psicologia Cognitiva (UFPE). Aluna de Pós-Graduação em Neuropsicologia (USP), São Paulo, São Paulo, Brasil. Endereço para correspondencia: Av. República do Líbano, 251, Sala 105, Pina, Recife, Pernambuco, Brasil, CEP: 51110-150. E-mail: giselda_mmm@yahoo.com.br.

** Doutor em Psicologia (René Descartes/Sciences Humaines-Sorbbone). Professor Titular do Departamento de Psicologia (UFRN), Natal, Rio Grande do Norte, Brasil. Endereço para correspondencia: Centro de Ciências Humanas, Letras e Artes/Departamento de Psicologia, S/N, Campus Universitário UFRN, Lagoa Nova, Natal, Rio Grande do Norte, Brasil, CEP: 59078-970. E-mail: falcao.jorge@ gmail.com
} 
faced in the reminder of courses. The present work investigates features of the structure of the classroom in a course on Statistics from the Psychology graduation curriculum. For such purpose, we set the didactic contract as a theoretical guide, a "lunette" that allowed for observing the functional dynamics of the classroom, searching aspects that might be related to difficulties in the teaching-learning process. To enhance the analysis of the dynamics of the courses' performance, we carried out a comparative overview with a discipline having the usual structure characteristic from the Psychology graduation curriculum. This study is based not only on video-graphic registers of the classes, but in interviews with its professors as well. The compiled data was submitted to a clinicalinterpretative analysis, pointing to several differentiation factors between the two disciplines, among them: classroom dynamics and evaluation systems. Specific to the Statistics course, important aspects appeared as negative interferences to the learning process, such as excessive manipulation of mathematical/statistical algorithms without the aid of informatics and computed data-processing. This study points to the importance of clarity in establishing a syllabus with respect to content, objectives, and structure of the statistics discipline in Psychology courses, in order to outline ways of didactic/pedagogical improvement for its offer...

Keywords: Didactic Contract. Statistics. Psychology.

\section{Introdução}

O ensino de conteúdos conceituais, competências e habilidades relacionados à análise quantitativa de dados nos cursos de graduação em Psicologia tem se mostrado problemático, não só no Brasil como também em outros países (DA ROCHA FALCÃO, 2007; GARFIELD, 1995; GARFIELD; BEN-ZVI, 2007; GARFIELD; AHLGREN, 1988; PONTE; BROCARDO; OLIVEIRA, 2005; SANTALÓ, 2001; SILVA, 2000; SILVA; CAZORLA; BRITO, 1999; VENDRAMINI, 2000).

Análise quantitativa de dados abarca aqui desde a consideração crítica do lugar que esse tipo de ferramenta ocupa no contexto de escolhas metodológicas do pesquisador em Psicologia, até o uso de testes estatísticos descritivos e inferenciais para o resumo de informações e teste de hipóteses. No contexto da formação acadêmica brasileira em Psicologia, um primeiro aspecto a ser considerado para a compreensão das dificuldades acima aludidas diz respeito ao fato de que um conteúdo curricular central, a Estatística (descritiva e inferencial-probabilística), tem sua origem em uma área de conhecimento (a Matemática) para além do núcleo tradicional do curso.

O estudo aqui reportado buscou contribuir tanto para uma melhor compreensão das dificuldades de ensino-aprendizagem desse domínio de conhecimento no cenário acadêmico dos cursos de Psicologia, como também em termos de caminhos voltados para a oferta pedagógica dos conteúdos e competências em questão. Tal contribuição baseou-se em dados de pesquisa voltados para a análise de atividade pedagógica no contexto da disciplina de Estatística, oferecida em bases regulares a alunos do curso de graduação em Psicologia de instituição pública-federal de ensino superior do nordeste do Brasil. Conforme será discutido mais adiante, a presente pesquisa elegeu a noção de contrato didático (BROUSSEAU, 2000) 
como um construto teórico utilizado como referência analítica para abordagem do processo de ensino-aprendizagem. Ou seja, através do contrato didático buscou-se compreender elementos relevantes na estruturação da dinâmica da sala de aula que ora facilitam, ora dificultam a aprendizagem; salientando que esses elementos estão aquém (ou além!) dos conteúdos didáticos abordados.

De acordo com D'Amore (2007), a ideia de contrato didático surgiu com o objetivo de estudar o fracasso típico reservado ao domínio da Matemática escolar apresentado por estudantes que, de maneira geral, conseguiam um bom desempenho em outros domínios curriculares. De fato, os trabalhos iniciados por Guy Brousseau nos anos de 1970, na França que caracterizaram o início, neste país, do movimento denominado "Didatique des Mathématiques" (Didática da Matemática - conforme Lombard, 1993) - chamaram a atenção para a importância de um conjunto de regras e prescrições, explícitas e implícitas, e baseadas em crenças, representações sociais e atitudes, que regulavam e balizavam o funcionamento da sala de aula de conteúdos matemáticos em qualquer nível de ensino. Os trabalhos de Brousseau refinaram a abordagem das peculiaridades e dificuldades do ensino de conteúdos matemáticos, à medida que aspectos relacionados à esfera do contexto psicossocial passaram a fazer parte do rol de aspectos a considerar, além dos habituais aspectos relacionados à didática de conteúdos propriamente dita. $\mathrm{O}$ construto teórico referente ao contrato didático se insere no âmbito mais amplo da teoria das situações didáticas, de importância central como referência teórica de pesquisa, e tratado a seguir.

\section{A Teoria das Situações Didáticas}

O movimento "Didática da Matemática" acima aludido teve como objetivo fundamental investigar o funcionamento das situações didáticas, caracterizado como o conjunto de relações que incluem o(a) professor(a), o(s) aluno(s) e o saber a ser ensinado-aprendido, em situação caracterizada por intencionalidade de ensino (BRITO MENEZES, 2006; GÁLVEZ, 2001). Guy Brousseau propôs uma representação gráfica que sumariza tal conjunto de relações em termos de um triângulo das situações didáticas (BROUSSEAU, 2000): 


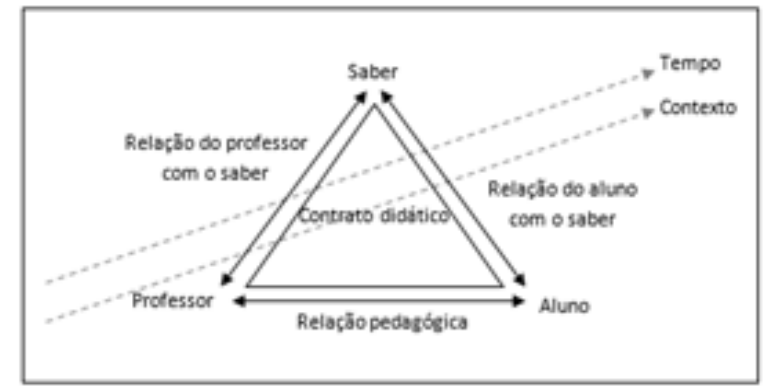

Figura 1 - Triângulo das situações didáticas Fonte: BRITO MENEZES (2006, p. 38).

A ilustração acima propõe um triângulo equilátero para a representação das situações didáticas, mas tal representação não deve ocultar o fato de que as relações que o(s) aluno(s) e o professor mantêm com o saber não são simétricas, como a representação pode sugerir. Além disso, essas relações também não são estáticas, sofrendo mudanças com o passar do tempo.

Tendo o ambiente escolar como contexto de realização, as situações didáticas ocorrem ao longo de um tempo que conta com três facetas. A primeira delas é referente ao sentido diacrônico, ou seja, à contagem linear do tempo (dias, horas, minutos). As outras duas facetas foram propostas por Chevallard (1991) e foram por ele chamadas de tempo didático - que se refere ao tempo marcado pelos programas de conteúdos escolares que devem ser cumpridos até o final de cada unidade didática - e tempo de aprendizagem (do aluno) - vinculado às rupturas e conflitos na construção de conhecimento, que caracteriza a complexidade do aprender (PAIS, 2002).

Há uma necessidade de relação mútua e contínua entre as facetas do tempo descritas. $\mathrm{O}$ tempo de aprendizagem deve estar em harmonia com o tempo didático, que, por sua vez, leva em consideração o tempo de aprendizagem na sua constituição. E ambos devem estar ao longo de todo processo submetidos ao tempo diacrônico. A quebra deste equilíbrio traz consequências negativas para o processo de aprendizagem dos alunos.

Além das diferentes facetas do tempo acima referidas, as situações didáticas exigem ainda uma "solidariedade funcional" entre os seus pólos (professor, aluno(s) e saber), como afirmam Jonnaert e Borght (2002). Para estes autores, "se esses três pólos definem um triângulo, uma abordagem didática interessa-se muito mais pelas relações que eles mantêm entre si do que por um ou outro deles considerado independentemente" (p. 56, grifo do autor). E é desse sistema de relações que emerge a noção teórica de contrato didático. 


\subsection{0 contrato didático}

Para entender o contrato didático conforme proposto por Brousseau (2000) é necessário se distanciar do sentido jurídico-legal e comum do termo "contrato". Como afirmam Jonnaert e Borght (2002), o que assegura a estabilidade no sentido estrito do termo é a cristalização das regras; ao passo que o que caracteriza o contrato didático é justamente a dinamização das regras, além do mesmo ter sua existência condicionada a um contexto de situação didática.

Não há na literatura uma definição única e tacitamente aceita de contrato didático. No entanto, as reformulações feitas pelo próprio Brousseau $(2000 ; 2001)$ na sua teoria e as contribuições de diversos pesquisadores que têm realizado estudos na área (BRITO MENEZES, 2006; BRITO MENEZES; CÂMARA DOS SANTOS, 2008; CHEVALLARD; BOSCH; GÁSCON, 2001; D’AMORE， 2007; JONNAERT; BORGHT, 2002; PAIS， 2002; SCHUBAUER-LEONI; PERRET-CLERMONT, 1997) permitem entender o contrato didático como um conjunto dinâmico de negociações explícitas e implícitas entre os pólos subjetivos do triângulo das situações didáticas, que encontram-se inseridos em um sistema de expectativas específicas e recíprocas mediado pelo conteúdo específico a ser trabalhado em sala de aula.

Jonnaert e Borght (2002) afirmam que a situação didática tem como função primeira proporcionar que o aluno modifique a relação que ele tem com o saber. Isso porque, no início de uma situação didática, o aluno possui uma relação "primária" com o saber; primária aqui entendida como uma relação que nem é de todo nova, pois o aluno não chega à sala de aula como uma "tábula rasa", e nem traduz um domínio do conteúdo formalizado por parte do aluno. Essa relação vai se modificando à medida que o aluno se apropria dos conteúdos trabalhados em sala de aula, e é mediada pelo professor (CÂMARA DOS SANTOS, 1997). Enquanto detentor do conhecimento que o aluno ainda não possui, o professor se constitui em agente de referência e poder diante dos alunos, conforme observa Pais (2002). Constata-se, pois, que as situações didáticas impõem a professor e alunos diferentes papéis a serem por eles assumidos e desempenhados. De acordo com Brousseau (2000; 2001), o papel mais difícil do professor é reconhecer e conferir sentido aos conhecimentos de modo a contextualizar o saber a ser ensinado-aprendido.

Muitas vezes referido como pólo "não humano" do contrato didático, o saber não deve ser interpretado como sendo estático (BRITO MENEZES; CÂMARA DOS SANTOS, 2008). Enquanto produto social, cultural e histórico, o saber precisa ser apresentado em um contexto significativo para os alunos, pois, como afirmam Jonnaert e Borght (2002), o fato de um determinado conteúdo ser inserido em um programa escolar não é por si só justificativa para 
que o mesmo seja aceito e aprendido pelos alunos. De acordo com Pais (2002), a crescente valorização educacional de uma disciplina mantém relação direta com o vínculo estabelecido pelo aluno entre o conteúdo estudado e um contexto que seja por ele compreensível e significativo.

No caso do estudo em questão, voltado para a oferta de disciplina de Estatística a estudantes graduandos de Psicologia, esse contexto tem especial importância. Considerada um sub-campo da Matemática Aplicada (DA ROCHA FALCÃO; RÉGNIER, 2000), a Estatística de fato se distancia dos saberes usualmente trabalhados nas demais disciplinas. Para Grácio e Garrutti (2005) muitos alunos dos cursos das Ciências Humanas acreditam que os conteúdos estudados nas disciplinas de Estatística não terão aplicabilidade em suas atuações profissionais, por não terem utilidade prática aparente. Esse ponto é agravado pelo fato de que os professores usualmente não têm disponibilidade e/ou preparação para trabalhar com os alunos a inserção da Estatística no contexto de determinada vertente da coleta e análise de dados, na pesquisa em Psicologia.

\section{Estatística e Psicologia}

A palavra estatística é derivada do adjetivo latino statisticum, cuja raiz etimológica é idêntica àquela do substantivo "estado". Da Rocha Falcão e Régnier (2000) afirmam que o surgimento do conhecimento estatístico situa-se historicamente nas antigas sociedades do Egito e da Mesopotâmia, em um contexto histórico-cultural de avaliação de produção agrícola para cobrança de impostos. Tal prática ganhou espaço no âmbito científico durante o século XVIII, recebendo de Godofredo Achenwall o nome de estatística (VENDRAMINI, 2000). No contexto sócio-cultural atual, a Estatística diz respeito a “(...) um domínio da matemática fundamentado em conceitos e ferramentas de resumo de informação e modelização de fenômenos, bem como ferramentas de avaliação probabilística de eventos, úteis para procedimentos de validação de hipóteses no trabalho científico" (NÓBREGA, 2010, p. 28).

Cada vez mais tem-se levado em consideração a necessidade de inserir conteúdos do domínio da Estatística na elaboração dos currículos escolares, desde o Ensino Fundamental até o Ensino Superior, uma vez que se considera que, desde o fim do século XX, estar alfabetizado supõe também competência para ler e interpretar dados (MINISTÉRIO DA EDUCAÇÃO E DO DESPORTO, 1997). Apesar do exercício da cidadania requerer cada vez mais uma formação - mínima que seja - em Estatística, o ensino de conteúdos desse domínio de conhecimento tem enfrentado sérios problemas, notadamente quando se considera o contexto 
acadêmico das Ciências Humanas, conforme aludido anteriormente.

Como exemplo disso, tem-se o estudo realizado por Vendramini e Brito (2001) com estudantes universitários das três áreas de conhecimento (Humanas, Exatas e Saúde), que elegeram a disciplina acadêmica que menos gostavam. A Estatística apareceu como resposta mais frequente para os alunos dos cursos das Ciências Humanas, notando-se inclusive uma diferença significativa nos efetivos das respostas dadas por esses alunos e por aqueles das ciências exatas e da saúde. Para Conners, McCown e Roskos-Ewoldsen (1998), se os alunos de Psicologia tivessem o direito de retirar da sua grade curricular uma disciplina, é bem provável que eles elegeriam a Estatística.

Muitos dos estudos que investigaram a rejeição que estudantes de Psicologia têm da Estatística se baseiam em avaliações de atitudes desses estudantes em relação a tal domínio curricular (como por exemplo Silva, Cazorla e Brito, 1999; Silva et al. 2002; Vendramini e Brito, 2001). Isso porque, para estes autores, as atitudes consistem em um dos componentes afetivos que participam efetivamente da aprendizagem de qualquer domínio de conhecimento (GÓMEZ CHACÓN, 2003). Porém são escassos na literatura da área estudos que remontem ao contexto psicossocial de sala de aula como um fator componente do processo ensinoaprendizagem.

Sendo assim, o estudo relatado no presente artigo buscou investigar aspectos cruciais presentes na estruturação da sala de aula de uma disciplina de Estatística oferecida no curso de Graduação em Psicologia. Para isso elegeu-se o contrato didático como um caminho teórico, uma "lente" através da qual fosse possível olhar a dinâmica de funcionamento da sala de aula, buscando aspectos que pudessem estar relacionados às dificuldades do processo ensinoaprendizagem.

\section{Método}

Enquanto fenômeno que emerge de situações didáticas, a abordagem do contrato didático só é permitida através da análise do funcionamento da sala de aula (MENEZES; LINS LESSA; BRITO MENEZES, 2007). Como afirma D’Amore (2007), o contrato didático é uma realidade em evolução, que acompanha a história da sala de aula. E é essa dinamicidade inerente ao contrato didático que impede que o seu surgimento, suas rupturas e negociações sejam sequer previsíveis, muito menos controláveis. Tais considerações nos conduziram a eleger a observação de caráter etnográfico e assistida pelo registro audiovisual como ferramenta de acesso ao contexto em questão. 
Não seria então possível escolher a priori aulas que indubitavelmente trariam elementos de contratos bem definidos. O critério de escolha de todas as aulas a serem filmadas foi acompanhar "aulas típicas" (que traduziriam a dinâmica corriqueira da sala de aula, cujo procedimento de escolha é descrito mais adiante) e "aulas críticas" (aquelas que antecediam as provas ou que abarcavam negociações acerca das atividades semestrais).

O curso de graduação em Psicologia que serviu de terreno para a realização do presente estudo tem na sua grade curricular duas disciplinas obrigatórias de Estatística - denominadas Estatística 2 e Estatística 4 - ambas regularmente ministradas por professores(as) do Departamento de Estatística da mesma Universidade. O estudo em questão elegeu como foco a disciplina Estatística 2 (a ser aqui denominada apenas Estatística) pelo fato da mesma ser a primeira a ser ministrada, sendo inclusive pré-requisito para a Estatística 4. Desse modo, excluindo os repetentes e eventuais alunos oriundos de outros cursos universitários, a disciplina Estatística é a primeira experiência dos alunos de Psicologia com o funcionamento de uma disciplina de Estatística em nível superior.

A fim de enriquecer a própria análise da dinâmica de funcionamento da disciplina descrita e suas especificidades, optou-se por analisar também as aulas de uma disciplina "típica" da cultura contratual do curso de Psicologia, no que diz respeito ao gerenciamento das aulas, à relação professor-aluno, ementa e sistema de avaliação. A escolha dessa disciplina foi feita contando com a participação dos alunos participantes da pesquisa, a quem se solicitou indicar qual a disciplina do curso que poderia ser considerada mais representativa das disciplinas da formação em psicologia, com base nesses critérios citados. Dentre as disciplinas por eles apresentadas, a que teve maior frequência de indicações (34,9\%) foi Psicologia do Desenvolvimento 1 (a ser aqui doravante referida como "Psicologia do Desenvolvimento").

Ao todo foram realizados onze momentos de observação. A análise e interpretação dos mesmos seguiram a seguinte sequência: 1) edição do material filmado, de forma a desconsiderar trechos considerados irrelevantes e ressaltar trechos considerados pertinentes; 2) exame intensivo e continuado do material filmado editado, até que fosse atingido o "ponto de saturação de inspeção" (PIRES, 2008); e 3) construção de narrativa interpretativa interligando os aspectos observados.

Além dos registros filmados esse estudo contou também com a realização de entrevistas com as professoras que ministraram as referidas disciplinas (Estatística e Psicologia do Desenvolvimento). Essas entrevistas tinham por objetivo buscar informações sobre a prática profissional das professoras, suas experiências de ensino tanto em seus Departamentos de origem como em cursos de outras áreas. As entrevistas foram audiogravadas e posteriormente 
transcritas.

Foi realizada uma análise qualitativa a partir da integração entre as narrativas decorrentes da análise dos registros filmados e as transcrições das entrevistas. Essa análise teve por objetivo proporcionar respostas para quatro questões que permearam esse estudo: 1) Quais as características do contrato didático na sala de aula da disciplina de Estatística oferecida aos graduandos em Psicologia?; 2) Quais as características do contrato didático estabelecido em uma disciplina "típica" do curso de Psicologia oferecida aos alunos desse Departamento?; 3) Em que tais características diferem entre si?; 4) Quais aspectos do contrato na disciplina de Estatística poderiam ajudar a entender eventuais dificuldades pedagógicas dos alunos de Psicologia ao cursarem tal disciplina?

\section{Resultados}

Os registros audiovisuais das aulas das duas disciplinas constituíram a base para uma análise qualitativa do funcionamento das salas de aula, que contou ainda com elementos produzidos a partir das entrevistas realizadas com as professoras.

Para fins de comparação entre as disciplinas de Estatística e Psicologia do Desenvolvimento foram pré-estabelecidos três parâmetros. O primeiro foi a relação tempo efetivo/tempo total de aula. O que foi chamado de tempo total se refere aos horários de início e término da aula pré-estabelecidos pelo Departamento de Psicologia com base na carga horária semestral de cada disciplina. Já o tempo efetivo teve seu início determinado pela chegada das professoras na sala de aula e o seu término delimitado pelo encerramento das atividades em sala. O segundo parâmetro de comparação, a gestão dos turnos de fala, diz respeito ao gerenciamento da fala por alunos e professora durante as aulas. Além disso foi também calculada a ausência dessa interação verbal. A unidade de contagem do tempo foi segundos, que será apresentado em termos percentuais, resultantes da média aritmética dos registros audiovisuais. O mesmo ocorrerá com relação ao tempo efetivo/tempo total.

Por fim, o terceiro parâmetro de comparação foi a presença de momentos de negociações do contrato didático, tanto no que se refere a elaboração de regras, como também a renegociações de regras quebradas. A seguir tem-se a apresentação resumida desses parâmetros em um quadro comparativo:

\begin{tabular}{|l|l|l|}
\hline \multirow{2}{*}{\multicolumn{1}{|c|}{ PARÂMETROS }} & \multicolumn{3}{c|}{ DISCIPLINAS } \\
\cline { 2 - 3 } & Estatística & \multicolumn{2}{c|}{ Psicologia do Desenvolvimento } \\
\hline Tempo efetivo/Tempo total & $70,66 \%$ & $93,08 \%$ \\
\hline Gestão dos turnos de fala & Ausência de interação verbal & Ausência de interação verbal \\
\hline
\end{tabular}




\begin{tabular}{|l|l|l|}
\hline \multirow{5}{*}{} & alunos-professora: 30,47\% & alunos-professora: 2,33\% \\
\cline { 2 - 4 } & $\begin{array}{l}\text { Gerenciamento da fala pela } \\
\text { professora: } 81,17 \%\end{array}$ & $\begin{array}{l}\text { Gerenciamento da fala pela } \\
\text { professora: } 91,27 \%\end{array}$ \\
\cline { 2 - 4 } & $\begin{array}{l}\text { Gerenciamento da fala pelos } \\
\text { alunos: } 18,83 \%\end{array}$ & $\begin{array}{l}\text { Gerenciamento da fala pelos } \\
\text { alunos: } 8,73 \%\end{array}$ \\
\hline Negociações do contrato didático & \multicolumn{1}{|c|}{ Presente } & \multicolumn{1}{|c|}{ Presente } \\
\hline
\end{tabular}

Quadro 1 - Parâmetros de comparação entre as disciplinas Estatística e Psicologia do Desenvolvimento. Fonte: Dados da pesquisa (2008/2009).

Observe-se que a relação tempo efetivo/tempo total na disciplina Psicologia do Desenvolvimento é consideravelmente maior do que na disciplina de Estatística, o que permite supor maior desperdício de tempo pedagógico nesta última. A defasagem em aproximadamente $30 \%$ do tempo efetivo de aula diante do tempo total pré-estabelecido pelo Departamento de Psicologia é um elemento importante desse contexto didático. Em nenhum dos momentos filmados, nem os alunos, nem a professora fizeram menção a essa defasagem, o que abre espaço para supor que essa maneira de gerenciar é antes um acordo - ainda que implícito - entre as partes do que uma imposição por qualquer uma delas. Diante desse fato torna-se inevitável o questionamento: essa defasagem do tempo relativo de aula guarda relação com algum grau de comprometimento da aprendizagem dos referidos alunos? Esse questionamento se legitima diante da constatação de uma postura de aceitação pacata dos alunos em relação aos conteúdos que estavam sendo trabalhados em sala de aula.

Com base não só na contagem matemática da relação tempo efetivo/tempo total, mas também nos registros filmados das aulas nas duas disciplinas, é possível fazer uma interessante reflexão acerca do gerenciamento do tempo. Na disciplina de Estatística, o tempo relativo parece ter sido gerenciado pelo tempo didático, no sentido proposto por Chevallard (1991). Ou seja, o tempo de aula estava submetido ao conteúdo didático programado para ser trabalhado em cada dia, de modo que o cumprimento da programação didática acarretava na finalização da aula.

Já no caso da disciplina Psicologia do Desenvolvimento, a relação do tempo efetivo com o tempo total é próxima de $100 \%$, ou seja, há uma maior coincidência entre o tempo efetivo de aula e o horário determinado pelo Departamento de Psicologia. Tal fato permite supor que, nessa disciplina, o tempo efetivo foi gerenciado pelo tempo diacrônico. Ou seja, encerra-se a aula porque ela está na hora de terminar, observando-se uma continuidade de trabalho de um mesmo conteúdo em aulas sequenciais.

No que se refere à gestão dos turnos de fala, observa-se uma relativa equiparidade em relação aos percentuais de fala das professoras de Estatística e de Psicologia do Desenvolvimento $(81,17 \%$ e $91,27 \%$, respectivamente), com pouca participação dos alunos, em 
termos de tempos de fala, em ambas as disciplinas (18,83\% e $8,73 \%$, respectivamente). No entanto, chama-se aqui atenção para o fato de que a fala dos alunos na disciplina de Psicologia do Desenvolvimento é decorrente de uma demanda dos próprios alunos, seja para tirar dúvidas ou para fazer comentários sobre o conteúdo trabalhado em sala. Já no caso da disciplina de Estatística, a fala dos alunos surge como respostas às constantes perguntas que a professora faz aos mesmos, no decorrer das resoluções de questões.

Nesse aspecto, o que também diferencia as disciplinas é justamente a ausência de interação verbal entre alunos e professora. Na disciplina de Psicologia, a ausência de interação ocorre em 2,33\% do tempo efetivo de aula. Já na disciplina de Estatística esse percentual é de $30,47 \%$, ou seja, aproximadamente $1 / 3$ do tempo efetivo de aula. E o mais importante aqui não é a ausência de interação verbal per se, mas o que motiva essa ausência: o fato dos alunos estarem copiando do quadro as questões a serem resolvidas e suas subsequentes resoluções. Acredita-se que este é um outro fator que limita a aprendizagem do conteúdo em questão por parte dos alunos, nem que seja por privá-los de um tempo maior para exercitar o conteúdo trabalhado em sala de aula.

Em relação às negociações, apesar das duas disciplinas terem apresentado momentos de negociações entre alunos e professora, esses momentos foram consideravelmente mais frequentes na disciplina de Psicologia, quer seja por falta de espaço para negociações na disciplina de Estatística, quer seja por falta de necessidade das mesmas. Apesar do cronograma entregue pela professora de Estatística aos seus alunos conter apenas as datas das provas e o conteúdo das mesmas, a programação do semestre parece não ter sofrido alterações. $\mathrm{O}$ único momento registrado de negociação referente ao cronograma ocorreu em decorrência de uma falta da professora, como mostrado no quadro a seguir:

\begin{tabular}{|l|l|}
\hline Extrato de aula & $\begin{array}{l}\text { P.E. (Professora de Estatística): Pra evitar de termos uma aula extra, eu vou passar } \\
\text { pra vocês uma lista de exercícios, certo? Na próxima segunda eu tiro dúvidas da } \\
\text { lista de classe e já entro com o conteúdo }\end{array}$ \\
& [os alunos perguntam se ela vai mandar a lista por e-mail. Ela diz que sim, e que \\
& eles têm que fazer em casa] \\
& Por que se isso não acontecer a gente vai ter que entrar em aula extra \\
\cline { 2 - 2 } & Aluna: Não professora! \\
\cline { 2 - 2 } & P.E.: Então se esforcem para fazer a lista, ok? \\
\hline
\end{tabular}

Quadro 2 - Recorte 1 de aula na disciplina de Estatística Fonte: Dados da pesquisa (2008).

Por outro lado, nos registros das aulas da disciplina de Psicologia do Desenvolvimento foram observados diversos momentos de negociações/renegociações de regras, sejam eles referentes a realização de aula-extra, a não ocorrência de aula próxima a um feriado, a modificações na execução da aula planejada previamente pela professora, como exemplificado 
no quadro a seguir:

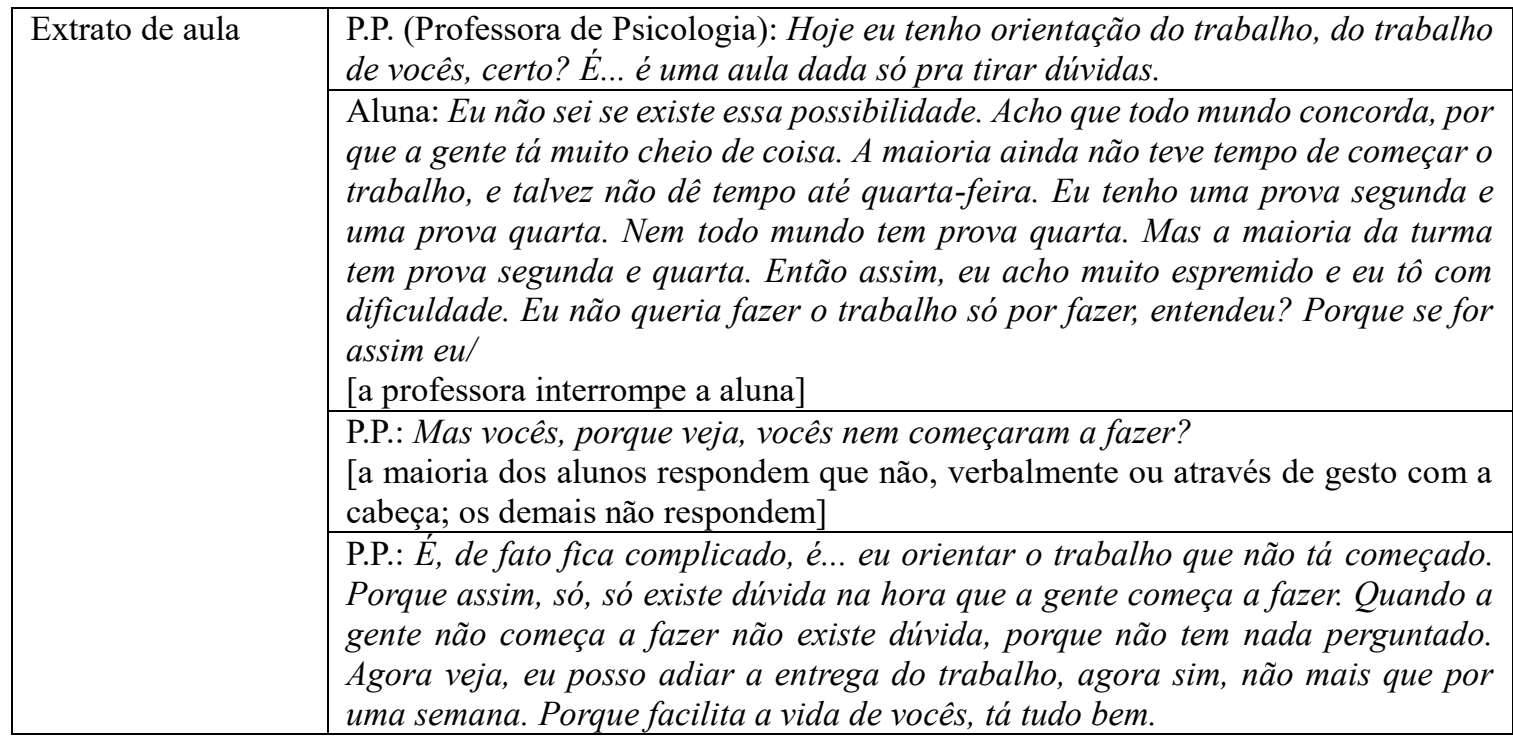

Quadro 3 - Recorte 1 de aula na disciplina de Psicologia do Desenvolvimento Fonte: Dados da pesquisa (2009).

É importante observar que em momentos de negociação/renegociação como o exemplificado acima, na aula da disciplina de Psicologia do Desenvolvimento, há uma certa disponibilidade por parte da professora para rever e renegociar regras de funcionamento da disciplina. Ou seja, a professora por instantes se destituiu da posição soberana de poder que ocupa por delegação contratual usual, como afirma Pais (2002). Ainda que a palavra final seja sua, fica claro que ela ponderou sua decisão a partir do que foi colocado pelos alunos.

Os resultados apresentados até aqui guardam relação com os três parâmetros de diferenciação previamente estabelecidos. Entretanto, outros fatores diferenciaram as disciplinas de Estatística e de Psicologia do Desenvolvimento.

Ao longo dos semestres letivos, as aulas de Estatística seguiram um padrão tradicional de funcionamento de sala de aula, com a professora ministrando aulas expositivas. Já na disciplina de Psicologia do Desenvolvimento, dos cinco momentos de aula registrados, três contaram com o que foi denominado "outras atividades", que consistiram, por exemplo, na apresentação de um vídeo relacionado ao conteúdo programático para posterior discussão entre alunos e professora. Foi interessante ainda a constatação de que nos dias em que se fizeram presentes, essas atividades ocuparam uma média de 58,6\% do tempo relativo de aula. Ou seja, mais da metade das aulas em questão não guardavam semelhança com o funcionamento de uma sala de aula tradicional, baseada em aulas expositivas.

Outro fator responsável pela diferenciação entre as duas disciplinas foi o sistema de avaliação utilizado. Na disciplina de Psicologia do Desenvolvimento não houve prova no sentido tradicional do termo. A avaliação semestral foi composta por diversas atividades, do 
tipo trabalhos escritos, seminários e questões com pontuação cumulativa para compor uma nota. Por outro lado, a única forma de avaliação na disciplina de Estatística foi a prova tradicional, no sentido há pouco mencionado. $\mathrm{O}$ dia da prova nessa disciplina parece ser dotado de uma importância soberana em relação aos demais dias de aula do semestre letivo, como pôde ser constatado na maneira que a professora pede silêncio aos alunos, oferecendo como motivo para um bom comportamento o seguinte argumento: "nossa prova é próxima aula". Ainda em relação à prova, e nessa mesma aula, foi possível perceber uma postura desafiadora da professora diante dos seus alunos, como sugere o recorte a seguir:

\begin{tabular}{|l|l|}
\hline \multirow{2}{*}{ Extrato de aula } & $\begin{array}{l}\text { P.E. (Professora de Estatística): Os alunos têm um mês pra aperrear o professor; o } \\
\text { professor só tem um dia, viu? Sentiram, né? }\end{array}$ \\
\cline { 2 - 2 } & Aluno: [vira-se para a pesquisadora e pergunta] Gravou isso? \\
\hline
\end{tabular}

Quadro 4 - Recorte 2 de aula na disciplina de Estatística. Fonte: Dados da pesquisa (2008).

É possível então observar que as disciplinas de Estatística e de Psicologia do Desenvolvimento apresentaram dinâmicas de funcionamento de sala de aula claramente diferentes. No entanto, além dos fatores já apresentados foram constatados aspectos específicos do contrato didático estabelecidos na disciplina de Estatística que podem ajudar a entender eventuais dificuldades dos graduandos em Psicologia ao cursarem tal disciplina.

Em alguns momentos das aulas filmadas foram observadas transposições de regras de contrato didático oriundo de outros ambientes de ensino-aprendizagem (BROUSSEAU, 2000) por parte da professora. Ou seja, algumas regras, legítimas enquanto emergentes de um contexto pedagógico - a sala de aula de Estatística em cursos das Ciências Exatas - passam a ser aplicadas no contexto atual, sem negociação prévia entre alunos e professora. O quadro a seguir ilustra essa situação:

\begin{tabular}{|c|c|}
\hline \multirow[t]{7}{*}{ Extrato de aula } & $\begin{array}{l}\text { P.E. (Professora de Estatística): Item } 1 \text {. } \\
\text { [a professora se refere aos itens que compõem a primeira questão: letras (a), (b) e } \\
\text { (c)] }\end{array}$ \\
\hline & Aluna:27,9. \\
\hline & P.E.: 27,932. Item 2. \\
\hline & Aluna: 32,8 . \\
\hline & P.E.: 32,852. Item 3 . \\
\hline & Aluna: $47,2$. \\
\hline & $\begin{array}{l}\text { P.E.: Pelo amor de Deus, sejam pirangueiros }{ }^{l} \text { com outras coisas. Deixem de } \\
\text { "pirangar" dígitos. Por que vocês têm que economizar depois da virgula, hein? } \\
\text { Grafite? Papel? O que é? Que horror! Vocês tão (SIC) muito econômicos. }\end{array}$ \\
\hline & $\begin{array}{c}\text { Quadro } 5 \text { - Recorte } 3 \text { de aula na disciplina de Estatística. } \\
\text { Fonte: Dados da pesquisa (2008). }\end{array}$ \\
\hline
\end{tabular}

Note que, para os alunos, a presença de uma única casa decimal parece ser suficiente

\footnotetext{
1 "Pirangueiro(a)" (substantivo) é o termo corrente no linguajar do nordeste do Brasil para pessoa sovina, pouco propensa ao dispêndio de dinheiro ou outro tipo de bem. "Pirangar" é o verbo derivado desse termo.
} 
para a proposição da resposta, o que se choca com o nível de precisão demandado pela professora, que não se mostra satisfeita com essa "economia" de dígitos. No contexto das Ciências Exatas de fato trabalha-se com um nível de precisão numérica superior. O que chama a atenção é a ausência de questionamentos, por parte dos alunos, e explicações, por parte da professora, sobre essa convenção para aquele contexto específico.

Um outro aspecto importante da dinâmica de funcionamento da disciplina de Estatística diz respeito à ênfase dada pela professora ao uso de calculadoras, fato comum nos cursos que compõem a área das Ciências Exatas. De maneira geral, é como se o uso da calculadora legitimasse a aprendizagem de conteúdos de domínio de conhecimentos que envolvem cálculos a partir de fórmulas de algoritmos. Ora, o que se observa na prática da Estatística como ferramenta de pesquisa por parte de psicólogos-pesquisadores é o uso generalizado de ambientes informatizados de codificação e análise de dados, como é o caso do aplicativo, bastante difundido, SPSS (Statistical Package for Social Sciences) ${ }^{2}$. Talvez por esse motivo seja cada vez mais comum se deparar com discussões teóricas acerca de quanto de aprofundamento algoritmo-matemático deve estar presente no ensino da Estatística destinado aos alunos de outras áreas de conhecimentos, notadamente das Ciências Humanas (SILVA, 2000; VENDRAMINI, 1998). Como bem afirma Becker (1993, p. 47), “o conhecimento reveste-se de significado na medida em que é transformado, pela ação docente, em conhecimento para o grupo, não descaracterizando, por um lado, a identidade deste conhecimento e considerando, por outro, a identidade do grupo".

Apesar de enfatizar constantemente o uso da calculadora e a manipulação de algoritmos estatístico-matemáticos, a professora parece ter consciência de que os futuros profissionais de Psicologia - então graduandos - integrar-se-ão a uma prática usual da Estatística que se apoia no uso de ambientes informatizados de trabalho e tratamento de dados, ou contarão com o auxílio de profissionais estatísticos especializados.

Essas discussões não conduzem à ideia de abolir a Matemática do ensino da Estatística, o que seria absurdo e inconsistente do ponto de vista epistemológico. O que se faz necessário deixar claro é que a Estatística não se restringe a destreza no manejo de algoritmos.

O exercício de habilidades e competências matemáticas demandado pelo esforço de oferta de disciplinas de Estatística em cursos de Psicologia parece explicar as dificuldades inerentes ao processo ensino-aprendizagem em dois de seus três pólos, professores e alunos. $\mathrm{Na}$ opinião da professora de Estatística, expressa na entrevista inicial do estudo, esse contexto

${ }^{2}$ SPSS. Disponível em: http://www.spss.com/worldwide/template_view.cfm?Country_ID=22. Acesso em: 11 abr. 2011. 
acadêmico requer "desafios da didática para ir para um ambiente que o aluno não tem formação matemática, detesta fórmula". Talvez isso explique a frase pronunciada em sala de aula pela professora aos seus alunos de Psicologia no primeiro dia do semestre letivo: "nenhum professor de lá [Departamento de Estatística] quer vir para cá [Departamento de Psicologia]”.

Os alunos, por sua vez, reagem à estatística como um "corpo estranho" na sua formação acadêmica. Além da ênfase dada aos algoritmos estatístico-matemáticos, dois outros fatores apreendidos dos registros filmados das aulas e das entrevistas realizadas com as professoras participantes do estudo parecem contribuir para essa rejeição.

O primeiro deles, e não por ordem de importância, se refere ao fato da disciplina de Estatística não constituir o foco de formação desses alunos. Na entrevista realizada ao final do semestre letivo, ao responder à pergunta se havia diferença em ensinar Estatística no curso de Psicologia quando comparado ao curso de graduação em Estatística, a professora afirma: " $\mathrm{Na}$ psicologia os alunos são muito dispersos, falam mais do que - mãe de misericórdia! - é difícil você ser escutado. Você sai da sala de aula cansado, porque os alunos pra se concentrar é uma dificuldade" (Fonte: Entrevista com a professora, 2008). Seguindo essa mesma linha de questionamento, foi perguntado à professora de Psicologia do Desenvolvimento se havia diferença entre ensinar Psicologia para os graduandos em Psicologia quando comparado aos graduandos de outros cursos de graduação. Em resposta a essa pergunta a referida professora afirmou: "O nível que ele [o aluno] vai ter de engajamento é completamente diferente de uma [disciplina] que vai ajudar esporadicamente; então o nível de envolvimento é completamente outro" (Fonte: Entrevista com a professora, 2009).

O segundo fator é o momento do curso universitário em que a disciplina é ministrada terceiro período, em um total de dez. Também nesse aspecto, constatou-se, através das entrevistas, uma concordância entre as duas professoras que participaram do estudo. A professora de Psicologia do Desenvolvimento afirmou: "existe um hábito que eu acho nocivo no curso [de Psicologia], que é colocarem inicialmente no curso disciplinas de outros Departamentos (...) que a meu ver só deveria ser dado no último período, quando o aluno já sabe mais um pouco de Psicologia e pode buscar uma interface com as outras áreas. Quando ele entra no curso ele não busca interface nenhuma" (Fonte: Entrevista com a professora, 2009).

Para a professora de Estatística, os alunos de Psicologia "têm uma resistência de aprender estatística por, acredito, por falta de saber qual a utilidade da estatística no futuro, por uma falta de maturidade pelo fato do curso de estatística ser no começo do curso de psicologia, não ser mais na frente. Então eles não sabem a importância”" (Fonte: Entrevista 
com a professora, 2008).

Tal fato implica na necessidade de uma reflexão crítica acerca dos objetivos pedagógicos da disciplina de Estatística oferecida no curso de Psicologia. Além do comum acordo entre as duas professoras que participaram desse estudo - que a imaturidade desses alunos no período inicial dificulta a criação de interfaces entre esse conteúdo específico e os demais que compõem a sua formação acadêmica - esse elemento encontra respaldo na ideia difundida na literatura da área, segundo a qual uma aprendizagem bem sucedida mantém relação direta com um contexto de significado para o aluno.

O encaminhamento de propostas de melhorias pedagógicas anteriormente aludidas, possibilitadas pela abordagem do contrato didático, não se restringem a alunos de Psicologia e professores de Estatística, como indivíduos ou como grupo desconectado de instâncias sócioculturais mais amplas. Tal esforço de melhoria pedagógica abarca necessariamente instâncias institucionais mais abrangentes - a começar pelos departamentos e coordenações de cursos de Psicologia - a fim de aumentar a clareza das necessidades instrumentais desses alunos em termos de ementa, objetivos e organização da disciplina. Os novos contratos decorrentes dessas reflexões deverão preservar, por um lado, a "honestidade epistemológica" da Estatística (BRUNER, 2001; 1976) e, por outro lado, o lugar da Estatística na formação acadêmicoprofissional do graduando em Psicologia ou qualquer outro domínio das Ciências Humanas.

A noção de "honestidade epistemológica", tal qual proposta pelo psicólogo norteamericano Jerome Bruner (2001), diz respeito à busca de uma forma de apresentação de determinado conteúdo que faça justiça às peculiaridades e complexidades conceituais da noção tratada e, ao mesmo tempo, busque adequação ao nível de informação, interesses e limites do interlocutor. Tal noção traz, portanto, em seu bojo, o desafio maior da oferta pedagógica, de "tradução sem traição", ou seja, adaptação de determinado conteúdo às necessidades do aluno sem perverter (às vezes, inexoravelmente) a compreensão daquele conteúdo por parte do aluno.

Por outro lado, a questão do lugar da Estatística na formação profissional do futuro psicólogo (seja ele um profissional de atuação ou um pesquisador acadêmico) não pode prescindir de uma integração desse domínio curricular com outros domínios cruciais, relacionados à discussão da epistemologia da Psicologia (notadamente em termos da cientificidade da mesma), pluralidade de propostas teóricas de referência e suas conexões com métodos e técnicas. Isto, no bojo do aprofundamento do domínio geral da metodologia (frequentemente confundida com os métodos em si) em Psicologia, conforme a reflexão proposta por Machado, Lourenço e Silva (2000). Sem essa integração de reflexões, o lugar da quantificação no bojo da construção do conhecimento psicológico aparece como um aposto, ou 
imposto, e a disciplina de Estatística aparece como algo estranho, artificial, enfadonho e, sobretudo, fonte de sofrimento.

A ausência de auxílio pedagógico acaba por alimentar uma relação cíclica de causa e efeito entre os dois fatores apresentados; ou seja, o não reconhecimento da importância da Estatística por parte dos alunos de Psicologia gera uma ausência de busca por interfaces, que, por sua vez, acarreta no não reconhecimento da importância da Estatística. Nesse contexto, aliás, a origem departamental dos professores que usualmente ministram a disciplina, geralmente oriundos de departamentos de Matemática ou de Estatística, se constitui em fator complicador no que diz respeito à abordagem da Estatística de forma psicologicamente contextualizada. Experiências de oferta da disciplina de Estatística no bojo de disciplinas de “análises de dados" ministradas por professores-psicólogos (pesquisadores e usuários de ferramentas quantitativas de análise) têm mostrado resultados interessantes em termos de avanço do rendimento didático-pedagógico na formação de estudantes de psicologia (DA ROCHA FALCÃO, 2007; DA ROCHA FALCÃO; MEIRA, 2003).

\section{Conclusão}

O estudo em questão buscou obter subsídios acerca do contrato didático na disciplina de Estatística oferecida no curso universitário de Psicologia, através dos quais apontou elementos que interferem negativamente no processo ensino-aprendizagem desse domínio de conhecimento no referido contexto. O contrato didático não esgota a análise das fontes explicativas de dificuldades no domínio de conteúdo aqui explorado (ou em qualquer outro domínio de aprendizagem escolar).

Porém, ao eleger o contrato didático como "lente" através da qual se vai olhar as dificuldades de ensino-aprendizagem, o contexto de sala de aula deixa de ser um fator externo e passa a ser um componente de destaque no processo ensino-aprendizagem. $\mathrm{O}$ aprofundamento acerca da investigação do contrato didático em qualquer domínio de conhecimento formal (escolar/acadêmico) acaba assim por oferecer elementos de interface com as duas outras fontes de obstáculos de aprendizagem: a relação do professor com o saber a ser trabalhado em sala de aula e a relação dos alunos com tais conteúdos. Isso porque as relações estabelecidas entre os elementos envolvidos nas situações didáticas são eminentemente dialéticas (e não dualistas).

O presente estudo foi permeado pela convicção de que a formação acadêmica desses alunos se beneficia de uma reflexão adequada acerca da abordagem quantitativa, que traz contribuições extremamente importantes para a formação do graduando em Psicologia e em 
Ciências Humanas de modo geral, como pesquisador e como consumidor crítico em sua área de atuação profissional. Por conta desse aspecto, não convém absolutamente descartar essa vertente de formação da trajetória acadêmica dos graduandos de Psicologia e Ciências Humanas em geral, mas encarar seriamente caminhos de aprimoramento didático-pedagógico para sua oferta.

\section{Referências}

BECKER, F. A epistemologia do professor: o cotidiano da escola. Petrópolis: Vozes, 1993. 344p.

BRASIL. Parâmetros curriculares nacionais (PCN), 2, Matemática: Ensino de 1a. à 4a. série. Brasília: Secretaria de Educação Fundamental, 1997.

BRITO MENEZES, A. P. de A. Contrato didático e transposição didática: inter-relações entre os fenômenos didáticos na iniciação à álgebra na sexta série do Ensino Fundamental. 2006. 411 f. Tese. (Doutorado em Educação) - Centro de Educação, Universidade Federal de Pernambuco, Recife, 2006. Disponível em:

http://www.ce.ufpe.br/posemeducacao/documentos/Teses_2006/Anna_Paula_de_Avelar_Brito_Menez es.pdf. Acesso em: 17 mai. 2007.

BRITO MENEZES, A. P. A.; CÂMARA DOS SANTOS, M. Negociações, rupturas e renegociações do contrato didático: refletindo sobre a construção de significados numa sala de aula de matemática, na perspectiva dos fenômenos didáticos. In: LEÃO, L. M.; CORREIA, M. (Org.). Psicologia

cognitiva: construção de significados em diferentes contextos. São Paulo: Alínea, 2008. p. 63-87.

BROUSSEAU, G. Os diferentes papéis do professor. In: PARRA, C.; SAIZ, I. (Org.). Didática da matemática: reflexões psicopedagógicas. Porto Alegre: Artes Médicas, 2001. p. 48-72.

BROUSSEAU, G. Fundamentos e métodos da didáctica da matemática. In: BRUN, J. (Dir.) Didáctica das matemáticas. Lisboa: Instituto Piaget, 2000. p. 35-113.

BRUNER, J. S. Uma nova teoria da aprendizagem. Rio de Janeiro: Bloch Editores, 1976.

BRUNER, J. S. A cultura da educação. Porto Alegre: Artes Médicas, 2001.

CÂMARA DOS SANTOS, M. A relação ao conhecimento do professor de matemática em situação didática: uma abordagem pela análise do seu discurso. In: Reunião da ANPEd, 20., 1997, Caxambu. Anais... Caxambu, 1997. CD-ROM).

CHEVALLARD, Y. La transposition didactique. Paris: La Pensée Sauvage, 1991.

CHEVALLARD, Y.; BOSCH, M.; GASCÓN, J. Estudar matemáticas: o elo perdido entre o ensino e a aprendizagem. Porto Alegre: Artmed, 2001.336 p.

CONNERS, F. A.; MCCOWN, S. M.; ROSKOS-EWOLDSEN, B. Teaching of Psychology, v. 25, 1998. Disponível em:

http://www.questia.com/googleScholar.qst;jsessionid=KpTZJdjyL8GvOQ1T8DKDh3TKnSWh8yyd6 56JsrVG3nMBmWwVTZ!-660333660!-230775256?docId=77003236. Acesso em: 5 jun. 2009.

DA ROCHA FALCÃO, J. T. Dificuldades e caminhos para o ensino de ferramentas matematicoestatísticas de análise de dados a estudantes universitários de Psicologia. In: Encontro Nacional de 
Educação Matemática (ENEM), 9., 2007, Belo Horizonte. Anais... Belo Horizonte, 2007 (CD-ROM).

DA ROCHA FALCÃO, J. T.; RÉGNIER. J-C. Sobre os métodos quantitativos na pesquisa em ciências humanas: riscos e benefícios para o pesquisador. Revista Brasileira de Estudos Pedagógicos, Brasília, v. 81, n. 198, p. 229-243, mai./ago. 2000.

DA ROCHA FALCÃO, J. T.; MEIRA, L. R. Análise qualitativa e quantitativa na pesquisa em psicologia: divergências e complementaridades. In: Reunião Anual da Sociedade Brasileira de Psicologia (SBP), 23., 2003, Belo Horizonte. Anais... Belo Horizonte, 2003.

D’AMORE, B. Elementos de didática da matemática. São Paulo: Livraria da Física, 2007.

GÁlVEZ, G. A didática da matemática. In: PARRA, C.: SAIZ, I. (Org.). Didática da matemática: reflexões psicopedagógicas. Porto Alegre: Artes Médicas, 2001. p. 26-35.

GARFIELD, J. How students learn statistics. International Statistics Review, v. 63, n. 1, p. 25-34, 1995.

GARFIELD, J.; AHLGREN, A. Difficulties in learning basic concepts in probability and statistics: implications for research. Journal for Research in Mathematics Education, v. 19, n. 1, p. 44-63, 1988.

GARFIELD J.; BEN-ZVI, D. How Students Learn Statistics Revisited: A Current Review of Research on Teaching and Learning Statistics. International Statistics Review, v. 75, n. 3, p. 372-396, 2007.

GÓMEZ CHACÓN, I. M. Matemática emocional: os afetos na aprendizagem da matemática. Porto Alegre: Artmed, 2003. 255 p.

GRÁCIO, M. C. C.; GARRUTTI, E. A. Seleção de conteúdos estatísticos para a educação: uma análise de Dissertações e Teses. Educação Matemática em Revista, n. 18/19, p. 35-45, dez. 2005.

JONNAERT, PH.; BORGHT, C. V. Criar condições para aprender: o sócioconstrutivismo na formação do professor. Porto Alegre: Artmed, 2002.

LOMBARD, P. Existe-t-il une didactique des mathématiques? 1993. Disponível em: http://www.irem.uhp-nancy.fr/Lomb/nazaire.pdf. Acesso em: 24 jun. 2018.

MACHADO, A.; LOURENÇO, O.; SILVA, F. J. Facts, concepts, and theories: the shape of psychology's epistemic triangle. Behavior and Philosophy, n. 28, p. 1- 40, 2000.

MENEZES, M. B. de; LINS LESSA, M. M.; BRITO MENEZES, A. P. de A. A emergência dos fenômenos didáticos em sala de aula: a negociação de uma seqüencia didática em álgebra inicial. In: Encontro Nacional de Educação Matemática, 9., 2007, Belo Horizonte. Disponível em: http://www.sbem.com.br/files/ix_enem/Html/comunicacaoCientifica.html. Acesso em: 17 jun. 2018.

NÓBREGA, G. M. M. Contrato didático como construto teórico para a abordagem do processo ensino-aprendizagem: o caso do ensino de estatística para alunos do curso de psicologia. 2010. 123f. Dissertação (Mestrado em Psicologia Cognitiva) - Universidade Federal de Pernambuco, Recife. 2010.

PAIS, L. C. Didática da matemática: uma análise da influência francesa. 2. ed. Belo Horizonte: Autêntica, 2002. 127 p.

PIRES, A. P. Amostragem e pesquisa qualitativa: ensaio teórico e metodológico. In: POUPART, J. (Org.). A pesquisa qualitativa: enfoques epistemológicos e metodológicos. Petrópoles: Vozes, 2008, 
p. 154-211.

PONTE, J. P.; BROCARDO, J. OLIVEIRA, H. Investigações matemáticas na sala de aula. Belo Horizonte: Autêntica, 2005. 152 p.

SANTALÓ, L. A. Matemática para não matemáticos. In: PARRA, C.; SAIZ, I. (Org.). Didática da matemática: reflexões pedagógicas. Porto Alegre: Artes Médicas, 2001. p. 11-25.

SCHUBAUER-LEONI, M. L.; PERRET-CLERMONT, A. N. Social interactions and mathematics learning, In: NUNES, T.; BRYANT, P. (Ed.). Learning and teaching mathematics: an international perspective. Hove: Psychology Press, 1997. p. 265-283.

SILVA, C. B. da; Atitudes em relação à estatística: um estudo com alunos de graduação. 2000. 157p. Dissertação. (Mestrado em Educação) - Faculdade de Educação, Universidade Estadual de Campinas, Campinas. 2000. Disponível em: http://libdigi.unicamp.br/document/?code=vtls000213558. Acesso em: 16 abr. 2009.

SILVA, C. B. da; CAZORLA, I. M.; BRITO, M. R. F. de; Concepções e atitudes em relação à Estatística.1999. Disponível em: http://www.inf.ufsc.br/cee/pasta1/art2.html. Acesso em: 4 mar. 2009.

SILVA, C. B. da; BRITO, M. R. F. de; CAZORLA, I. M.; VENDRAMINI, C. M. M. Atitudes e relação à estatística e à matemática. 2002. Disponível em: http://scielo.bvspsi.org.br/scielo.php?pid=S1413-82712002000200011\&script=sci_arttex\&tlng=pt. Acesso em: 16 jun. 2008.

VENDRAMINI, C. M. M. Dificuldades em matemática e solução de problemas em Estatística. 1998. Disponível em: http://www.sbempaulista.org.br/epem/anais/mesas_redondas/mr14Claudette.doc. Acesso em: 04 mar. 2009.

VENDRAMINI, C. M. M. Implicações das atitudes e das habilidades matemáticas na aprendizagem dos conceitos de estatística. 2000. 252 f. Tese. (Doutorado em Educação) - Faculdade de Educação, Universidade Estadual de Campinas, Campinas. 2000. Disponível em: http://libdigi.unicamp.br/document/?code=vtls000248392. Acesso em: 22 jul. 2008.

VENDRAMINI, C. M. M.; BRITO, M. R. F. de Relações entre atitude, conceito e utilidade da estatística. 2001. Disponível em: http://scielo.bvs-psi.org.br/scielo.php?pid=S1413$85572001000100007 \&$ script=sci_arttex\&tlng=pt. Acesso em: 16 jun. 2008.

Submetido em 27 de Junho de 2018. Aprovado em 06 de Abril de 2019. 